\title{
Research use of leftover newborn bloodspots: Attitudes of Canadian geneticists regarding storage and informed consent requirements
}

\author{
Julie Richer, $M D^{1}$, Musie S. Ghebremichael, PhD', Albert E. Chudley, MD ${ }^{3}$, Walter M. Robinson, MD", \\ Benjamin S. Wilfond, $M D^{5,6}$, and Mildred Z. Solomon, $E d D^{7}$
}

\begin{abstract}
Purpose: Leftover newborn spots can provide a powerful research tool as a population-wide DNA bank. Some provinces/states store them for more than 20 years; however, parents are usually not informed of the retention of leftover newborn spots. To examine the opinions of Canadian geneticists regarding permission for leftover newborn spots storage for research purposes and the associated risks, a web-based survey was distributed to all members of the Canadian College of Medical Geneticists with a valid e-mail address $(n=209)$ and completed by 78 respondents (37\%). Results: The majority of respondents (73\%) favored opt-out notification for retention of samples that would be held for longer than 2 years. For research on multifactorial conditions using leftover newborn spots originally banked without parental permission, geneticists favored different types of permission depending on the level of identifiable information attached to samples. Thirty-eight percent were concerned that information pamphlets that state that leftover newborn spots will be stored and may be "a source of DNA for research" would lead to a decreased participation in newborn screening. Twenty-eight percent believed that group stigma or family anxiety was likely to result from using nonidentified leftover newborn spots to study multifactorial conditions. Conclusion: The concerns of this knowledgeable cohort supports the critical importance of public engagement about both the potential risks and societal benefits associated with the use of leftover newborn spots in research as policy for leftover newborn spots is developed. Genet Med 2011:13(4):305-313.
\end{abstract}

Key Words: newborn screening, genetic research, biobank, DNA banking, ethics, genotype, molecular research, geneticists

$\mathrm{N}$ ewborn screening, one of public health's major successes, began in the 1960 s with phenylketonuria testing. ${ }^{1}$ Newborns are typically screened in North America without parental permission because of the potential public health value. ${ }^{2}$ Although in the United States some states only permit withdrawal for religious reasons, in Canada, parents can decline newborn

From the ${ }^{1}$ Department of Genetics, Children's Hospital of Eastern Ontario, Canada; ${ }^{2}$ Department of Biostatistics, Harvard School of Public Health, Boston, Massachusetts, ${ }^{3}$ Department of Biochemistry and Medical Genetics, University of Manitoba, Winnipeg, Manitoba, Canada, ${ }^{4}$ Center for Biomedical Ethics and Society, Vanderbilt University, Nashville, Tennessee; ${ }^{5}$ Trueman Katz Center for Pediatrics, Seattle Children's Research Institute; ${ }^{6} \mathrm{Di}-$ vision of Bioethics, Department of Pediatrics, University of Washington School of Medicine, Seattle, Washington; and ${ }^{7}$ Division of Medical Ethics, Department of Global Health and Social Medicine, Harvard Medical School, Boston, Massachusetts.

Julie Richer, MD, Children's Hospital of Eastern Ontario (CHEO), 401 Smyth Road, Ottawa, ON, Canada K1Y 4W9. E-mail: juricher@cheo.on.ca.

Disclosure: The authors declare no conflict of interest.

Submitted for publication January 8, 2010.

Accepted for publication August 10, 2010

Published online ahead of print October 1, 2010.

DOI: $10.1097 /$ GIM.0b013e3181f69da0 screening for any reason. Many parents are not even aware that newborn screening is performed. ${ }^{3}$ The leftover newborn spots (LONBS) have been stored, also typically without parental permission, for variable periods of time extending beyond 20 years in some jurisdictions in North America. ${ }^{4,5}$ In the past, LONBS had limited potential value, but they now represent a powerful research resource in the context of high throughput genomic technologies. ${ }^{6,7}$ Recently, tandem mass spectrometry ${ }^{8-10}$ greatly increased the number of conditions screened for. As a result, numerous information pamphlets distributed to parents are being updated to reflect these new changes, although most still do not address the issue of storage of leftover samples.

In Canada, most practitioners and leaders in the field seem inclined to endorse educating the public about the LONBS storage practices. ${ }^{11}$ However, many questions remain. What type of conditions should be investigated using LONBS? How should confidentiality be protected? Should parental permission be sought for spots stored for only a brief period of time? What information should be provided to parents? For how long should these LONBS be stored? Should consent be obtained once the child is 18 years to continue to store the samples?

Answering these questions is becoming increasingly urgent in the current social context where use of leftover biological material in research is gaining increasing public scrutiny. Recent examples where researchers and/or governmental bodies have not only been criticized but also punished by law courts for using leftover biological material without proper consent for secondary use include the cases of the Havasupai tribe ${ }^{12}$ and of use of residual blood spots in Texas. ${ }^{13}$

LONBS differs from biobanks built explicitly for research in that questions pertaining to (1) the appropriate types of consent, ${ }^{14-16}$ (2) mechanisms to ensure privacy protection and confidentiality of participants, (3) benefit sharing, ${ }^{17,18}$ and (4) how and when to return research results and incidental findings to participants ${ }^{19-21}$ have been well explored in the literature. ${ }^{22-32}$ In 2005, Avard et al. ${ }^{11}$ surveyed newborn screening laboratories in Canada and found that retention practices varied widely. The stakeholders whom they surveyed (40 individuals including representatives from provincial Newborn Screening laboratories, health professional associations, policy makers, consumer groups, and the research community attending the Garrod Association meeting, a annual metabolic meeting in Canada) supported use in research of anonymous LONBS with research ethics board (REB) approval. However, these survey respondents also expressed concerns that gathering consent for research purposes might interfere with the screening process.

Geneticists are a key group of professionals and are in a privileged position to understand the elements at play in genetic research and the extent of risks associated with use of different types of samples. We reasoned that it would be important to discover whether this sophisticated group has significant concerns regarding use of these samples. Indeed, if they did, this 
would suggest the need for broader public discussion on the use of these spots. It would also help to identify the issues, which should be given priority in those discussions. We chose to study only Canadian geneticists, as the cultural context is distinct from the United States, and the presence of a universal health care system may lead to different perceptions of the risks associated with results derived from research.

More specifically, the goal of our survey was to assess Canadian geneticists' views on (1) what would constitute an appropriate type of permission for storage and research uses of LONBS and (2) whether samples that include increasingly identifiable information should be subject to more explicit approaches to permission.

\section{METHODS}

We developed a survey instrument based on pilot testing with three Medical Ethics Fellows from Harvard University and two Genetics Residents from the University of Manitoba. The research protocol was approved by the Health REB, Bannatyne Campus, University of Manitoba, and by the Board of Directors of the Canadian College of Medical Geneticists (CCMG). An e-mail containing a live link to the web-based survey was sent by the CCMG to all its members on February 15, 2007. Data collection started on February 15, 2007, and ended on March 14, 2007. A reminder e-mail was sent on March 1, 2007.

\section{Vignettes about permission and oversight}

We used vignettes to assess respondents' opinions about (1) appropriate approaches to permission for storage of LONBS, (2) the appropriate level of oversight required to use LONBS for research on multifactorial conditions, (3) the impact on parents' willingness to participate in newborn screening, if the research use of leftover deoxyribonucleic acid (DNA) from LONBS were publicly disclosed, and (4) the likely risks associated with the research use of LONBS. Vignettes were structured to reveal how respondent attitudes might change according to different levels of identifiable information. All vignettes specified that respondents were to assume that LONBS had initially been collected without parental permission (as this reflects the current common situation in Canada).

We used a six-point Likert-scale and collapsed answers into either agree or disagree to assess agreement with different types of consent for storage of LONBS (each question was independent, and respondents could, therefore, agree with more than one strategy for seeking consent). We also calculated the mean level of agreement by weighting each respondent's answer as follows: completely disagree was assigned a score of 1 , disagree 2, somewhat disagree 3 , somewhat agree 4 , agree 5 , and completely agree 6 . The total score for each category (notification, verbal, and written) was then divided by the number of respondents.

\section{Definition of types of samples by level of identifying information}

In the survey instrument, we explicitly defined the terms anonymous, generalized, linked, and identified, as defined in Figure 1.

\section{Perceived risks associated with the research use of LONBS}

We asked five questions about risks. These particular risks were selected because they represent broad categories of risks, which are often cited as potentially of concern. ${ }^{33,34}$ If respon-
Anonymous: These are specimens without any identifying information and without a link to an individual patient source; in this type of research, there is no possibility of linking clinical or other data to the specimen, and no possibility of contacting the individual with research results.

Generalized: These are specimens that have some demographic information such as gender, ethnicity, or geographic location, but this information is limited to the one that was written directly on the newborn screening card (i.e. there is no information about subsequent clinical data, such as diagnosis of diseases) and the information provided is insufficient to lead to identification of the individual. In this type of research, there is no possibility of contacting the individual with research results, but there is the possibility of identifying research results with a specific social group, e.g. "Native male children" or "females born in Edmonton in the 1970's."

Linked: These are specimens for which the unique identifiers have been removed after linking them to a database, which permits identification of some phenotypic information through a code. For example, linked specimens could be provided with information on the diagnosis and billing codes related to the particular patient, without divulging identifying information on the patient to the researchers. In this type of research, it can be possible to contact the individual with research results.

-Identified: These are specimens that have unique identifiers attached (name or health insurance number); in this type of research, clinical data can be linked directly to the specimen, and it is possible to contact the individual with research results.

Fig. 1. Definitions of identifiability.

dents answered "yes" to at least one of these questions, they were categorized as having a greater global perception of risk for the purposes of correlation analysis.

\section{Definition of type of practice, researcher, and provincial origin}

We categorized respondents as clinicians or laboratory practitioners. We defined clinicians as respondents who indicated either clinical genetics or clinical metabolics as their primary area of practice. We defined laboratory practitioners as individuals who indicated clinical molecular laboratory, clinical metabolic laboratory, or clinical cytogenetic laboratory as their primary area of practice. We distinguished between researchers and nonresearchers based on respondents who indicated whether they devote $25 \%$ or more of their time to research (respondents who did not specify the amount of time they devoted to research were not categorized.) Finally, we categorized respondents as to whether their primary geographic area of practice was the province of Quebec or not (respondents who did not specify their province of practice were included in the latter group). Respondents from Quebec were analyzed separately, because consent for newborn screening there includes an opt-in component, whereas only a notification with opt-out option is presented in the rest of Canada.

\section{Statistical analysis}

Fisher exact tests were used to compare response rates among unordered categories (e.g., gender: male versus female; geographic area of practice: Quebec versus other states; and area of practice: clinician versus laboratory), and the Jonckheere-Terpstra test was used for ordered categories (e.g., percentage of time allotted to research: $<25 \%$ versus $\geq 25 \%$ ). Tetrachoric and polychoric correlations were used to measure correlations between answers to questions in various sections of the survey. A coefficient of correlation with a positive value was interpreted as implying a direct association between the two variables. A variable in direct linear correlation would have a maximum coefficient correlation of +1 , and a variable with no association would have a coefficient of correlation of 0 , and a correlation $>0.3$ was interpreted as statistically significant.

\section{RESULTS}

\section{Demographics}

The CCMG has 233 members; 13 did not provide an e-mail address, and 11 e-mails did not reach the intended recipient; 
Table 1 Demographic characteristics of 78 geneticists (\%)

\begin{tabular}{lc}
\hline & Survey respondents, $N(\%)$ \\
\hline Mean age & $51.3 \mathrm{yr}(\mathrm{SD}=12 \mathrm{yr})$ \\
Sex & $31(10)$ \\
Male & $41(53)$ \\
Female & $6(8)$ \\
Nonrespondents & \\
Primary area of practice & $39(50)$ \\
Clinical genetics & $1(1)$ \\
Clinical metabolics & $11(14)$ \\
Clinical molecular laboratory & $4(5)$ \\
Clinical metabolic laboratory & $14(18)$ \\
Clinical cytogenetics laboratory & $5(6)$ \\
Other & $4(5)$ \\
Nonrespondents & \\
Percentage of time allocated to research & $53(68)$ \\
$<25$ & $11(14)$ \\
$25-40$ & $6(8)$ \\
$41-75$ & $3(4)$ \\
$>75$ & $5(6)$ \\
Nonrespondents & \\
\hline
\end{tabular}

Participants were asked to answer the above questions but were still allowed to proceed through the survey if they refused to answer a question which could potentially uniquely identify them given the small number of geneticists in Canada.

therefore, 209 members received the survey. A total of 78 Canadian geneticists (Table 1) completed the survey (response rate $=37 \%$ ). Eight participants could not be categorized according to their type of practice. The province of origin of the respondents was not statistically significantly different from the provincial distribution of the members of the CCMG. Unfortunately, the CCMG did not have data on the average age of their membership, and they allowed members to select more than one affiliation without specifying if the majority of their practice is clinical or laboratory, and we could, therefore, not compare our data to the total membership.
Answers from clinicians were not significantly different from those of laboratory practitioners. There were also no statistical differences between the answers of researchers and nonresearchers. We have, therefore, collapsed across these categories in presenting the data.

\section{Perception of the risks as likely to be associated with the research use of LONBS}

Table 2 describes respondents' ratings of five risks as likely or unlikely to occur, if nonidentified LONBS were used for research on multifactorial conditions. Most respondents (72\%) believed that it is unlikely that any of the five risks assessed would occur, but $28 \%$ rated at least one of the five risks as "likely" (global perception of risk). Across the five risks, group stigma and family anxiety were seen as the most likely, by $18 \%$ and $15 \%$ of respondents, respectively.

Those who perceived any of the five risks were also more likely to agree with the need for written parental permission for retention of LONBS for more than 2 years (correlation of $0.45)$.

\section{Perceived impact of disclosing retention of DNA on participation in newborn screening}

Concern that changing the wording in the information pamphlet provided to parents to say that "the blood collected for newborn screening will be kept and may be used as a source of DNA for research" would lead to decreased participation in newborn screening was expressed by $26(38 \%)$ respondents (Table 3).

\section{Perception of appropriate form of permission for storage}

The majority of all respondents agreed with seeking permission for storage of LONBS by informing the population that samples are to be retained and that it is possible to withdraw one's sample (public notification with opt-out option, from here on referred to as notification). As Table 4 indicates, this agreement stands true whether the samples are to be retained for more than 2 years (73\% agreement: $29 \%$ completely agreed, 35\% agreed, and 9\% somewhat agreed) or past the age of majority (69\% agreement: $16 \%$ completely agreed, $42 \%$ agreed, and $11 \%$ somewhat agreed). As respondents were asked to rate their agreement with each strategy for seeking consent, they could agree with more than one strategy. Other options presented to respondents included requesting verbal consent and/or requesting written consent; as per Figure 2, these options obtained a lower rate of agreement than the notification strategy.

Table 2 Perception of risks for research on multifactorial/polygenic conditions, $N=66$

"Below you will find a few statements about the potential risks associated with utilization of non-identified leftover newborn spots for research on multifactorial/polygenic conditions. Please read each statement carefully. Then tell us whether you think each situation is likely or unlikely to occur."

Who answered "likely," $N(\%) \quad$ Who answered "unlikely," $N(\%)$

Group stigma will develop against particular subgroups of contributors

Patients/families will suffer increased anxiety

Patients' ability to obtain employment will be impaired

Patients' ability to obtain insurance will be impaired

Patients/families will suffer deterioration of familial relationships

$\begin{array}{cc}12(18) & 54(82) \\ 10(15) & 56(85) \\ 1(2) & 65(98) \\ 2(3) & 64(97) \\ 1(2) & 65(98)\end{array}$


Table 3 Perceived impact of disclosing retention of DNA on participation in newborn, $N=68$

"The Minister of Health for your province has suggested changing
the information pamphlet for newborn screening to say that 'the
blood collected for newborn screening will be kept and may be
used as a source of DNA for research.' In your option, how would
this chance affect the number of parents who give permission for
newborn screening?"
This change would
$\begin{aligned} & \text { Increase participation in newborn } \\ & \text { screening }\end{aligned}$
$\begin{aligned} & \text { Decrease participation in newborn } \\ & \text { screening }\end{aligned}$
Not change participation in newborn
screening
Participants were allowed to select only one answer.

Notably, agreement with a notification strategy was correlated with judging that disclosing retention of DNA from newborn screening would not decrease participation in screening programs (coefficient of correlation of 0.46 ).

However, agreement with a notification strategy was lower among Quebec respondents (Table 5 and Fig. 3). For samples retained past the age of majority, only $42 \%$ of Quebec respondents $(5 / 12)$ agreed with a notification strategy in contrast to the $78 \%$ of non-Quebec respondents who agreed $(P=0.02)$. For samples kept for more than 2 years, 58\% (7/12) of Quebec respondents versus 75\% (38/51) of non-Quebec respondents agreed with a notification strategy, although because of the very small number of Quebec respondents, this trend did not reach statistical significance $(P=0.30)$.

\section{Type of permission perceived as required for use of LONBS in research on multifactorial conditions not related to newborn screening}

As Figure 4 indicates, the approach to permission favored for the use of LONBS in research on multifactorial conditions varied according to their potential identifiability. For all types of samples, most respondents believed that, at minimum, REB review was necessary. For anonymous and "generalized" samples, slightly more than two thirds of respondents did not think that written parental permission was necessary. For linked LONBS, even though most respondents $(67 \%)$ believed that some written parental permission was necessary, $31 \%$ favored REB approval only (and 2\% incorrectly believed that no type of permission was required). The group that preferred to obtain written permission was evenly split between those who thought it would be appropriate to obtain a single permission for use in research (blanket consent) and those who thought that parental permission should be specific for each protocol. For identified LONBS, $78 \%$ of respondents favor a specific parental permission for each protocol.

\section{DISCUSSION}

Thirty-eight percent (38\%) of our respondents felt that including information in parental educational pamphlets that say "the blood collected from newborn screening will be kept and may be used as a source of DNA for research" would decrease participation in newborn screening. Moreover, $28 \%$ of those who answered the question expected at least one kind of research risk to occur, if nonidentified LONBS were to be used in research on multifactorial conditions. These findings about the perception of risk highlight the paramount importance of encouraging public discussion, among both health care professionals such as geneticists and members of the public. Such discussions should focus on societal benefits and purposes of conducting research with LONBS and potential risks.

Table 4 Perceptions regarding types of permission, which should be required to store LONBS

No. who agreed/No. respondents

who answered the question (\%)
Mean agreement score

If the province wants to keep Guthrie cards more than $2 \mathrm{yr}$,

No direct parental permission is required provided active efforts are made to inform the public about DNA banking of newborn spots and of the $48 / 66(73)$

possibility to withdraw one's sample at any time.

It should get verbal permission from the parents.

It should get written permission from the parents.

If the province wants to keep Guthrie cards more than $18 \mathrm{yr}$,

No direct parental permission is required provided active efforts are made to inform the public about DNA banking of newborn spots and of the possibility to withdraw one's sample at any time.

It should get verbal permission from the parents.

$10 / 64(16)$

It should get written permission from the parents.

$22 / 64(34)$

We used a six-point Likert-scale and collapsed answers into either agree or disagree to assess agreement with different types of consent for storage of LONBS (each question was independent, and respondents could, therefore, agree with more than one strategy for seeking consent). The options somewhat agree, agree, and completely agree were collapsed into "agree," whereas the options completely disagree, disagree, and somewhat disagree were collapsed into "disagree."

The mean level of agreement was calculated by weighting each respondent's answer as follows: completely disagree was assigned a score of 1 , disagree 2 , somewhat disagree 3 , somewhat agree 4 , agree 5 , and completely agree 6 . The total score for each category (notification, verbal, and written) was then divided by the number of respondents. 


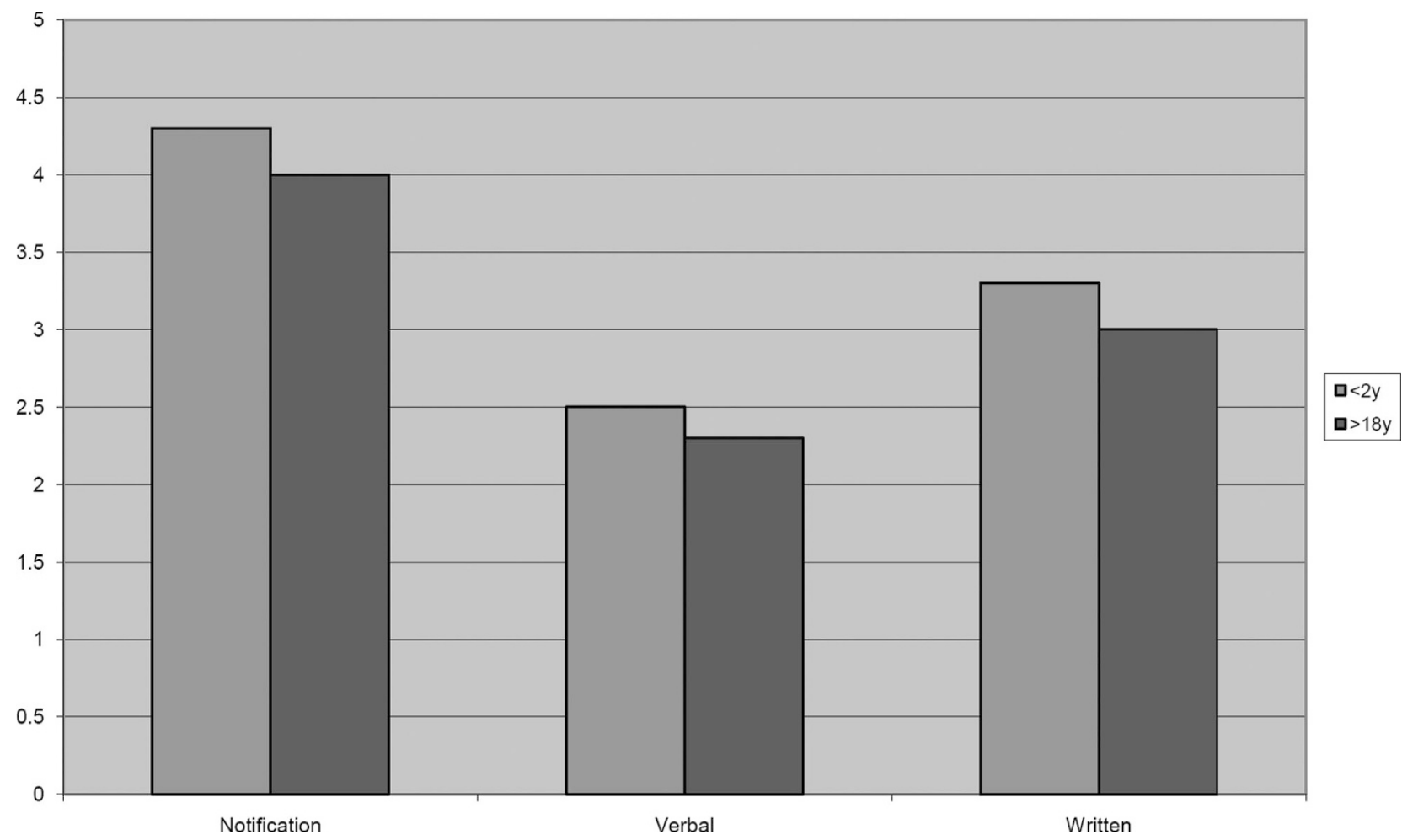

Fig. 2. Mean level of agreement with different strategies to seek consent.

Table 5 Perceptions of Quebec respondents regarding types of permission, which should be required to store LONBS

No. who agreed/No. respondents who answered the question (\%)
Mean agreement score

If the province wants to keep Guthrie cards more than $2 \mathrm{yr}$,

No direct parental permission is required provided active efforts are made to inform the public about DNA banking of newborn spots and of the possibility to withdraw one's sample at any time.

It should get verbal permission from the parents.

It should get written permission from the parents.

If the province wants to keep Guthrie cards more than $18 \mathrm{yr}$,

No direct parental permission is required provided active efforts are made to inform the public about DNA banking of newborn spots and of the possibility to withdraw one's sample at any time.

It should get verbal permission from the parents.

It should get written permission from the parents.

We used a six-point Likert-scale and collapsed answers into either agree or disagree to assess agreement with different types of consent for storage of LONBS (each question was independent and respondents could therefore agree with more than one strategy for seeking consent). The options somewhat agree, agree and completely agree were collapsed into "agree" while the options completely disagree, disagree and somewhat disagree where collapsed into "disagree."

The mean level of agreement was calculated by weighting each respondent' answer as follow: completely disagree was assigned a score of 1 , disagree 2 , somewhat disagree 3 , somewhat agree 4 , agree 5 and completely agree 6 . The total score for each category (notification, verbal, written) was then divided by the number of respondents.

Geneticists are a key group of professionals and are in a privileged position to understand the nature and extent of risks associated with the use of different types of samples in genetic research. One might argue that if a group of highly knowledgeable professionals perceive risks, the general public may be even more likely to perceive such risks. However, health care professionals might be more risk averse, or more inclined to worry about human subjects' protection, than the average citizen. Indeed, a review of several studies about the public's views regarding consent for biobanking found that large numbers of citizens do not perceive significant risk and would consent for future unspecified uses of their biospecimens, whereas many 


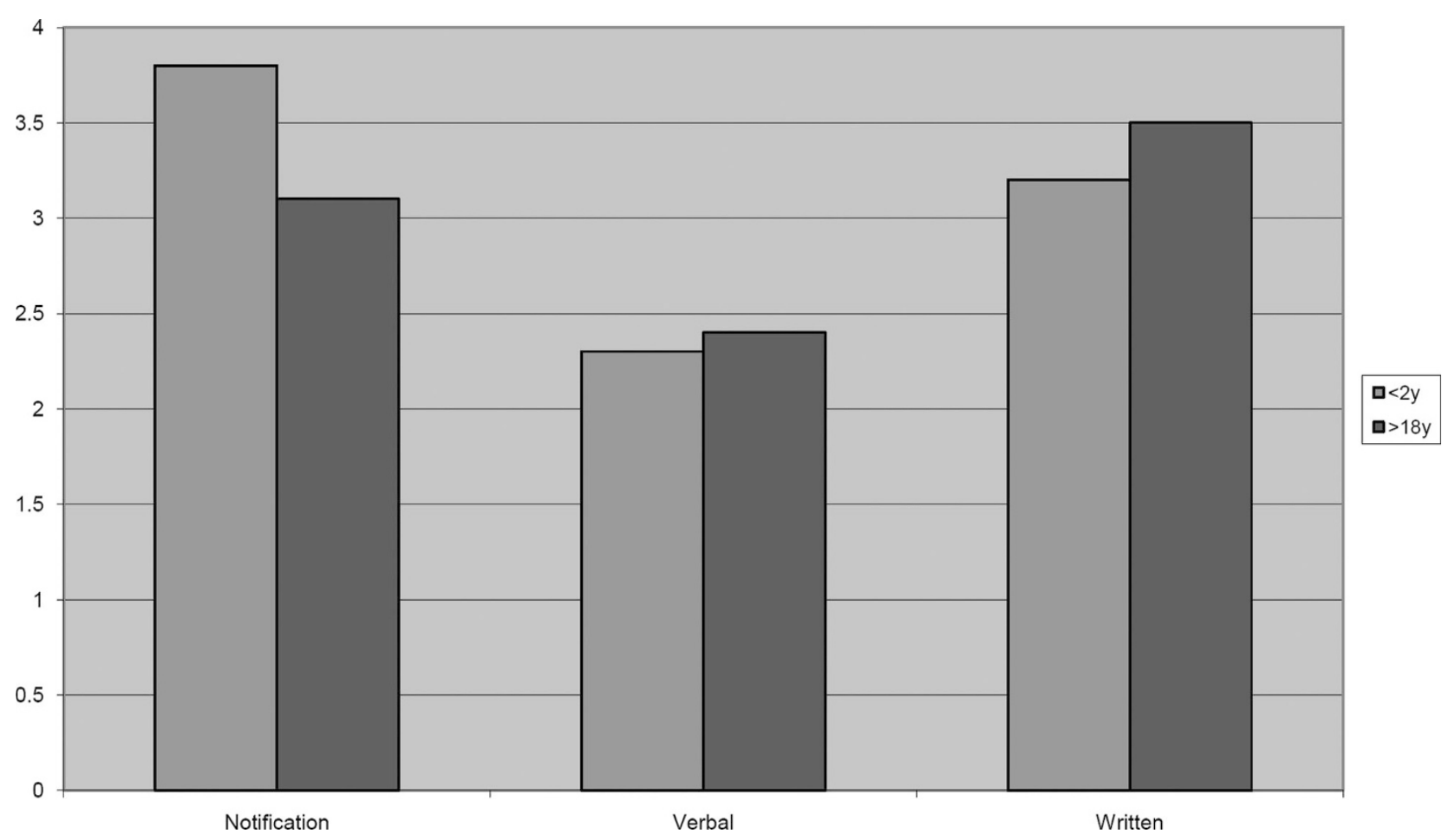

Fig. 3. Mean level of agreement from Quebec respondents with different strategies to seek consent.

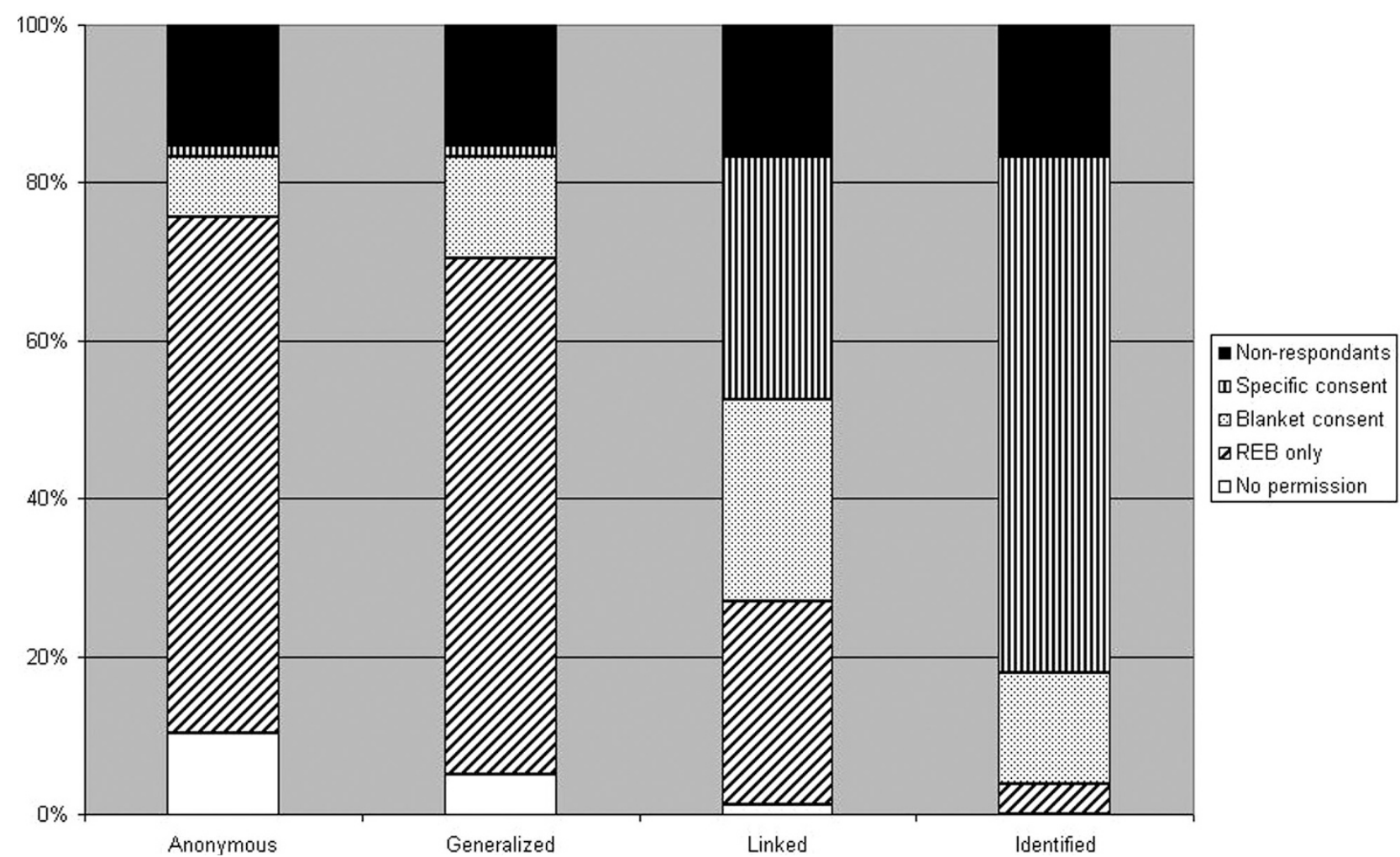

Fig. 4. Preferred type of permission according to identifiability of samples. 
professionals have called for more stringent forms of consent. ${ }^{35}$ In short, we cannot infer from our results how the general public is likely to perceive requests to use LONBS for research. Indeed, there is likely to be no "one" general public but rather a range of opinions. Moreover, these attitudes remain to be discovered empirically. What we can conclude, however, is that $38 \%$ of geneticists are concerned that retention and use for research of DNA for LONBS may have a negative impact on newborn screening. These concerns can be interpreted as worry about the impact on public trust of plainly stating that the blood spots will be a source of DNA for research. This finding should be seen as a bright yellow light, cautioning us to proceed with mindfulness. If $38 \%$ of such a sophisticated and highly knowledgeable group perceives risk and worries about impact on the public's trust, it behooves the research community to take steps to preserve that trust particularly at a time where the general public has clearly stated that they want to be consulted about the use of their biological materials for research. Within the last year, parents in Texas successfully sued the state and obtained a new law mandating that parents be told how the state intends to manage their child's genetic material and given the opportunity to prohibit such use by the state. ${ }^{13}$ Moreover, in the past few months, the Havasupai tribe successfully sued researchers for improper use of their DNA, reminding not only the medical community but also the entire general public of the importance of transparency and of public engagement in decisions about use of leftover biological material in genetic research. ${ }^{12,36,37}$ Because, after all, these decisions concerns us all.

One can argue that there is a moral obligation to protect the public's trust in the health institution of newborn screening. The argument resides in the fact that research using LONBS is not for the direct benefit of individual patients, but newborn screening does directly benefit individual patients and that is its purpose. Therefore, jeopardizing public trust in newborn screening would not only undermine the ability of this institution to fulfill its public health mandate, but it would also undermine the best interests of individual newborns.

For all these reasons, researchers must seriously consider how best to preserve the public's trust. Top-down educational efforts that simply aim to inform or reassure the public are likely to be unhelpful at best, counterproductive and paternalistic at worst. Instead, we believe that authentic engagement with the nature of the problem should be promoted. Public engagements through structured processes of deliberative democracy have already been successfully deployed to encourage community discussions in Canada on the topic of biobanking. Secko et al. ${ }^{38}$ report on a highly structured set of strategies they used to reveal differences and points of consensus among citizens in British Columbia on the types of consent participants would be comfortable with in various kinds of biobanks. Their approach provides an excellent model for similar conversations that could be structured about the use of LONBS.

Moreover, there is some evidence that engagement per se, even when the public perceives risks associated with the activity for which consent is being sought, can contribute to greater, not lesser, public trust. It is in this context that our differential results from respondents from the province of Quebec are particularly enlightening.

Our survey asked respondents to rate their agreement with different strategies (notification, verbal consent, and written consent) for seeking consent to store LONBS. One may argue that this does not allow assessing the preferred strategy of each respondent. However, the aim of this work was not to impose a strategy but rather to evaluate which strategies, in the eyes of professionals, would be reasonable options to present to the public if we are to initiate a community consultation process. The type of permission selected by our respondents for storage parallels the type of permission sought for the newborn screening process itself. Most of our respondents preferred an opt-out notification strategy for storage of LONBS both for samples kept more than 2 years and for samples retained more than 18 years. However, respondents from the Province of Quebec were less likely to favor a notification strategy (particularly for samples retained more than 18 years) and instead favored written consent. Their responses parallel the way permission is obtained for newborn screening in Quebec. An opt-out notification strategy is used in all of Canada, except in Quebec, where a parental opt-in strategy is used. There, in addition to the blood sample drawn near birth, parents are also invited to take the initiative to mail a urine sample at 3 weeks of age (with an excellent compliance rate: $90 \%$ over 3 decades $^{39}$ ). The perceived requirement for a more stringent type of permission for storage of LONBS by Quebec respondents could represent more than a cultural difference. It may also be that, by including an opt-in component for the screening process, the population is de facto better informed about the process. Community consultation seeks to obtain a "buy-in" from the population, and one could argue that the $90 \%$ compliance rate with the opt-in component of newborn screening in Quebec reflects such a buy-in. Requesting a written consent (opt-in component) for storage of samples may, therefore, represent a stronger strategy for achieving community buy-in for the research use of LONBS. Such requests could also be promoted by community consultation. Community consultation could also allow sharing knowledge with the public and hearing potential ambivalence, thereby directly involving the population in decision making. Indeed, although traditionally poor trust was believe to be due to fear or lack of knowledge, increasing data support that trust is not only related to levels of fear or knowledge but also to the degree of public engagement. ${ }^{40,41}$

Avard et al. ${ }^{11}$ has shown that Canadian stakeholders expressed concerns that gathering explicit consent for secondary use might impair participation in screening. Our data only partially confirmed this finding. Although $38 \%$ of our survey respondents are concerned that disclosing that DNA derived from LONBS would be retained and potentially used for research might interfere with the screening process, we actually observed a positive correlation between participants who agreed with a notification strategy and those who believed that disclosing retention of DNA would not decrease participation in screening. Therefore, agreement with a notification strategy is probably not simply an avoidance strategy to try to minimize the potential negative impacts disclosure might have on public trust but a reflection of these respondents' sense of what is an appropriate level of protection.

The main limitation of this study is its modest response rate. However, this study differs from most survey research in that instead of sampling a subgroup of the population of interest, we presented the entire membership of the CCMG with an opportunity to express their opinion. Moreover, this study represents the largest sample published to date on the views of a key stakeholder group, 78 members of the CCMG. There is also ample research documenting the difficulty of reaching a response rate $>50 \%$ in surveys of physicians, and incentives are often used to reach that threshold. ${ }^{42,43}$ Moreover, online surveys have also been shown to obtain more modest response rates. ${ }^{44,45}$ A meta-analysis ${ }^{46}$ has not only documented a mean $34 \%$ response rate for online surveys but also has concluded that particular groups including physicians have even poorer response rate to online surveys. That we gathered responses from 
$37 \%$ of the total CCMG membership with an online survey without the use of incentives of any type may suggest that we captured the views of those with the greatest interest in the subject.

One may ask about the pertinence of surveying the opinions of medical geneticists because most of them do not necessarily participate in designing public policies regarding newborn screening. However, our findings have relevance beyond newborn screening and provide guidance regarding use of all types of stored leftover biological material in genetic research. In this regard, we believe that geneticists are an important group to survey because they are the professionals with the richest expertise in counseling for DNA-based tests and in interpreting the results of such testing. Clinical geneticists use DNA-based tests routinely in their practice including presymptomatic testing and testing using technologies susceptible to yield results of unclear clinical significance. Proficiency in obtaining informed consent (from adults or parental permission for children) for such testing is an integral part of the training of clinical geneticists. In this context, we believe that clinical geneticists are an important population to survey not only because of their involvement and understanding of newborn screening but also mainly because of their expertise and "hands-on" experience with the utilization of genomic technologies.

The geneticists who answered our survey favor seeking parental permission for storage of LONBS using an opt-out notification strategy. They favor sole REB approval for anonymous and generalized samples and increasing levels of oversight, as identifiability of the samples increases. For identified samples, geneticists believe specific consent for each protocol is required. For linked samples to be used in research, opinions were varied. Thus, study of this issue is needed to (1) promote reflection among stakeholders, (2) clarify beliefs about risk, (3) clarify types of consent perceived as appropriate, and (4) develop more nuanced policies about which types of results, derived from such research, should be returned to participants. Furthermore, a substantial minority believes that there is a likely risk of group stigma and heightened family anxiety, if even nonidentified LONBS are used in research. This finding emphasizes the necessity to develop well-designed methods of public engagement and civic discourse on the potential risks and likely societal benefits associated with the research use of these samples.

\section{ACKNOWLEDGMENTS}

The design of the survey, the data collection, and the preliminary draft were completed while Dr. Richer was completing the Fellowship in Medical Ethics in the Division of Medical Ethics, Department of Global Health and Social Medicine, at Harvard Medical School, Boston, MA. Her salary support was provided by the Department of Medical Genetics at the University of Manitoba, Canada.

\section{REFERENCES}

1. Guthrie R, Susi A. A simple phenylalanine method for detecting phenylketonuria in large populations of newborn infants. Pediatrics 1963;32:338343

2. Kharaboyan L, Avard D, Knoppers BM. Storing newborn blood spots: modern controversies. J Law Med Ethics 2004;32:741-748.

3. Therrell BL, Johnson A, Williams D. Status of newborn screening programs in the United States. Pediatrics 2006;117:S212-S252.

4. Laboratory specimen information for newborn screening in the U.S. in 2006, 2006. Available at: http://www2.uthscsa.edu/nnsis/. Accessed September 27, 2006.

5. Olney RS, Moore CA, Ojodu JA, Lindegren ML, Hannon WH. Storage and use of residual dried blood spots from state newborn screening programs. J Pediatr 2006;148:618-622.
6. Hollegaard MV, Grauholm J, Borglum A, et al. Genome-wide scans using archived neonatal dried blood spot samples. BMC Genomics 2009;10:297.

7. Hollegaard MV, Thorsen P, Norgaard-Pedersen B, Hougaard DM. Genotyping whole-genome-amplified DNA from 3- to 25-year-old neonatal dried blood spot samples with reference to fresh genomic DNA. Electrophoresis 2009;30:2532-2535.

8. Eggertson L. Canada lags on newborn screening. CMAJ 2005;173:23

9. Kaye CI, Accurso F, La Franchi S, et al. Newborn screening fact sheets. Pediatrics 2006;118:e934-e963.

10. National Newborn Screening and Genetics Resource Center, 2006. Available at: http://genes-r-us.uthscsa.edu/CA_nbsdisorders.pdf. Accessed September 20, 2010.

11. Avard DV, Vallance H, Greenberg C, Laberge C, Kharaboyan L, Plant M. Variability in the storage and use of newborn dried bloodspots in Canada: is it time for National standards? Genomics Soc Policy 2006;2: $80-95$.

12. Mello MM, Wolf LE. The Havasupai Indian tribe case-lessons for research involving stored biologic samples. $N$ Engl J Med 2010;363:204-207.

13. Texas' Newborn Screening Program. Available at: http://www.dshs.state.tx.us/ legislative/NBS-presentation-051710.ppt\#256,1. Accessed June 1, 2010.

14. Hansson MG, Dillner J, Bartram CR, Carlson JA, Helgesson G. Should donors be allowed to give broad consent to future biobank research? Lancet Oncol 2006:7:266-269.

15. Caulfield T, Upshur RE, Daar A. DNA databanks and consent: a suggested policy option involving an authorization model. BMC Med Ethics 2003; 4 :E1.

16. Clayton EW. Informed consent and biobanks. J Law Med Ethics 2005;33: $15-21$

17. Malinowski MJ. Technology Transfer in biobanking: credits, debits, and population health futures. J Law Med Ethics 2005;33:54-69.

18. Andrews LB. Harnessing the benefits of biobanks. J Law Med Ethics 2005;33:22-30.

19. Wilfond BS, Carpenter KJ. Incidental findings in pediatric research. $J$ Law Med Ethics 2008;36:332-340; 213.

20. Wolf SM, Lawrenz FP, Nelson CA, et al. Managing incidental findings in human subjects research: analysis and recommendations. $J$ Law Med Ethics 2008;36:219-248; 211 .

21. Ravitsky V, Wilfond BS. Disclosing individual genetic results to research participants. Am J Bioeth 2006;6:8-17.

22. Deschenes M, Sallee C. Accountability in population biobanking: comparative approaches. J Law Med Ethics 2005;33:40-53.

23. ACT on Biobanks no. 110/2000, 2000. Available at: http://ministryofhealth. is/laws-and-regulations/nr/31. Accessed October 10, 2006.

24. Elger BS, Caplan AL. Consent and anonymization in research involving biobanks: differing terms and norms present serious barriers to an international framework. EMBO Rep 2006;7:661-666.

25. Kaye J. Do we need a uniform regulatory system for biobanks across Europe? Eur J Hum Genet 2006;14:245-248.

26. Gibbons SM, Helgason HH, Kaye J, Nomper A, Wendel L. Lessons from European population genetic databases: comparing the law in Estonia, Iceland, Sweden and the United Kingdom. Eur J Health Law 2005;12: 103-133.

27. Rothstein MA. Expanding the ethical analysis of biobanks. $J$ Law Med Ethics 2005;33:89-101

28. Kaiser J. Genetics. U.S. hospital launches large biobank of children's DNA. Science 2006;312:1584-1585.

29. Rothstein MA. The role of IRBs in research involving commercial biobanks. J Law Med Ethics 2002;30:105-108.

30. Knoppers BM. Biobanking: international norms. J Law Med Ethics 2005; 33:7-14.

31. Regulations on the keeping and utilisation of biological samples in biobanks no. 134/2001, 2001. Available at: http://eng.heilbrigdisraduneyti.is/laws-andregulation $/ \mathrm{nr} / 684$.

32. Hens K, Nys H, Cassiman JJ, Dierickx K. Genetic research on stored tissue samples from minors: a systematic review of the ethical literature. Am J Med Genet A 2009;149A:2346-2358.

33. Marteau TM, Croyle RT. The new genetics. Psychological responses to genetic testing. BMJ 1998;316:693-696.

34. Davis DS. Genetic research \& communal narratives. Hastings Cent Rep 2004;34:40-49.

35. Wendler D. One-time general consent for research on biological samples. BMJ 2006;332:544-547.

36. Harmon A. Indian tribe wins fight to limit research of its DNA. NY Times, 2010.

37. After Havasupai litigation, Native Americans wary of genetic research. Am J Med Genet 2010;152A

38. Secko DM, Preto N, Niemeyer S, Burgess MM. Informed consent in biobank research: a deliberative approach to the debate. Soc Sci Med 2009;68:781-789.

39. Auray-Blais C, Giguere R, Lemieux B. Newborn urine screening programme 
in the province of Quebec: an update of 30 years' experience. $J$ Inherit Metab Dis 2003;26:393-402.

40. Cunningham-Burley S. Public knowledge and public trust. Community Genet 2006;9:204-210.

41. Wynne B. Public engagement as a means of restoring public trust in science-hitting the notes, but missing the music? Community Genet 2006; 9:211-220

42. Thorpe C, Ryan B, McLean SL, et al. How to obtain excellent response rates when surveying physicians. Fam Pract 2009;26:65-68.

43. Grava-Gubins I, Scott S. Effects of various methodologic strategies: survey response rates among Canadian physicians and physicians-in-training. Can Fam Physician 2008;54:1424-1430.

44. Lozar Manfreda K, Bosnjak M, Berzelak J, Haas I, Vehovar V. Web surveys versus other survey modes. A meta-analysis comparing response rates. Int $J$ Market Res 2008;50:79-104.

45. VanGeest JB, Johnson TP, Welch VL. Methodologies for improving response rates in surveys of physicians: a systematic review. Eval Health Prof 2007;30:303-321.

46. Shih TH, Fan X. Comparing response rates from web and mail surveys: a meta-analysis. Field Methods 2008;20:249-271.

\section{In Memoriam: Charles J. Epstein, MD}

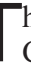

he entire medical genetics community mourns the passing of

Charles J. Epstein and joins his wife, Lois, their four children, and their grandchildren in honoring his memory. Charlie's training included a B.A. in Chemistry from Harvard (Phi Beta Kappa), an M.D. from Harvard Medical School (AOA), 2 years as an Internal Medicine resident at Peter Bent Brigham Hospital, 2 years at the National Institutes of Health in the laboratory of Chris Anfinsen working on protein chemistry, and 1 year as a medical genetics fellow with Arno Motulsky in Seattle.

Charlie returned to the National Institutes of Health for 3 years as chief of the Section on Genetics and Development before coming to the University of California, San Francisco, with a Research Career Development Award (NICHD) to start and lead the Division of Medical Genetics in the Department of Pediatrics. He remained there for the rest of his career, becoming the director of the interdepartmental UCSF Program in Human Genetics and building a comprehensive and highly integrated service, training, and research program that became a model for other universities to emulate.

His early work in preimplantation biochemistry led to a better understanding of $\mathrm{X}$ inactivation and grew into a lifetime interest in the consequences of chromosomal imbalance (the title of his 1986 book). Charlie developed a mouse model of Down syndrome to study the pathogenic mechanisms of the syndrome. He became a driving force in many national and international Down syndrome organizations, and after chairing the National Down syndrome Society from 1979 to 2000, he was honored when the society renamed its annual awards the Charles J. Epstein Down syndrome Research Award.

During his busy career he found time to serve the genetics community as editor-in-chief of the American Journal of Human Genetics for 7 years, as president of the American Society of Human Genetics, as president of the American College of Human Genetics, and as president of the American Board of Medical Genetics.

Charlie's brilliance and thoughtful work were recognized by his many honors and awards. Among them were the March of Dimes Colonel Harland Sanders Award for Lifetime Achievement in the field of Genetic Sciences, the Distinguished Research Award of the Arc of the United States, the William Allan Award of the ASHG, and the 2010 ASHG McKusick Leadership Award. He was additionally honored by the establishment of the Charles J. Epstein Professorship in Human Genetics at UCSF, by a Lifetime Achievement Award from the American College of Medical Genetics, and by the Buck Institute for

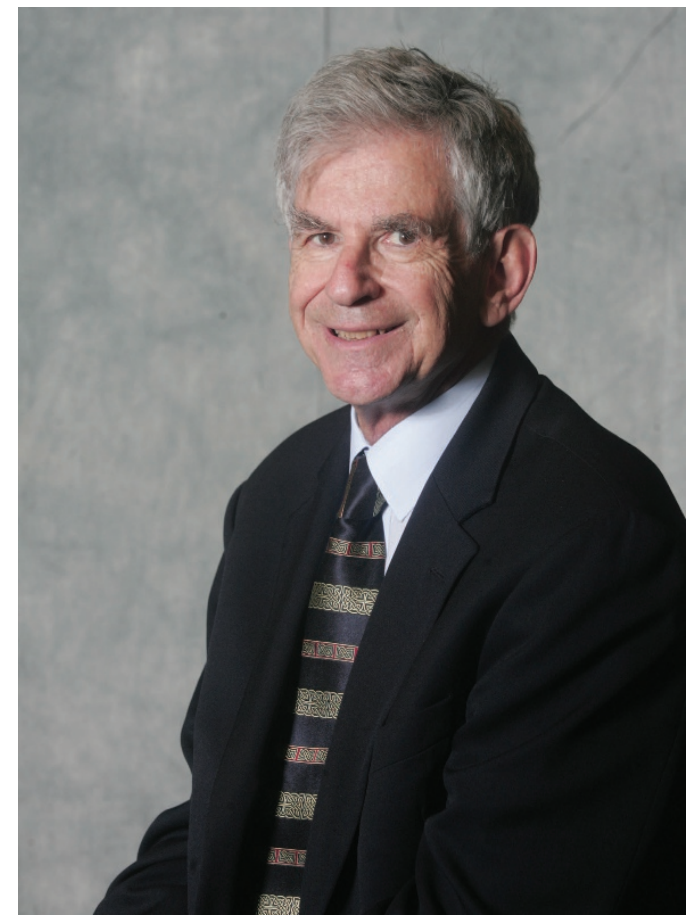

Research in Aging establishing an annual Charles J. Epstein Lecture Series. The UCSF Institute of Human Genetics recently established a visiting professorship in honor of Charlie and his wife, Lois, a renowned cancer researcher.

In the course of his career, Charlie trained 120 postdoctoral fellows, providing them with the model of the consummate clinician-scientist that he was. As one of his earliest fellows, I know I speak for all of them in expressing our respect, reverence, and love for Charlie, and that he will be missed by all of us.

Mitchell S. Golbus, MD

Professor Emeritus

University of California

San Francisco, California 